\title{
Paradoxes of the Knowledge Society Some Considerations on the Italian Situation
}

\author{
By Gerardo Pastore*
}

\begin{abstract}
This paper intends to present some paradoxical aspects within the Italian route towards the Knowledge Society, and to propose a critical analysis of the problematic transition from theory to practice of the Knowledge Society. Starting from a concept of permanent education put forward by UNESCO in the Seventies, and continuing with the more recent "Lisbon Strategy", the plan seems to be clear: "becoming the most competitive and dynamic knowledge-based economy in the world". However, despite successes in some important sectors, the ongoing evaluation of the Lisbon Strategy has highlighted difficulties in economical growth, employment, innovation and social inclusion. Furthermore, the ongoing financial crisis has worsened these problems. As such, the relaunching of the "Europe 2020 Strategy" as a way out of the crisis, in line with the Lisbon proposals, confirms that the path towards the Knowledge Society is inevitable. According to the statistics released by OECD and EUROSTAT, Italy has fallen behind because of evident contradictions: even though the idea of a knowledge society is celebrated on the level of rhetoric, public resources for strategic sectors remain insufficient. Is there a shift from the illusion of progress to disappointment?
\end{abstract}

Keywords: Crisis, Italy, Knowledge society, Public policies.

\section{Introduction}

The aim of this paper is to present some paradoxical aspects within the Italian route towards the Knowledge Society, and to propose a critical analysis of the problematic transition from theory to practice of the Knowledge Society. When we discuss the Knowledge Society, we set ourselves the problem of the directions of development of contemporary societies. In this sense, from the point of view of analysis of social change, some scholars show a paradigm shift: that is, a transition from a material dimension to an intangible dimension, from hardware to software, from realisation to conception, from markets to networks. Based on this transformation, the need for a Knowledge Society appears as completely evident and takes the form of novelty compared with the past. But it is not so obvious that the routes that started at a national level will lead to positive results in terms of social inclusion, expansion of the cultural base, and job and professional satisfaction. This aspect of the reflection refers to a scope of issues that have special relevance. If attention is shifted from the subject to the social system, the attitudes of the latter have to be carefully considered, and the preparation and inclination of the system are not necessarily entirely consistent with the proposal of a Knowledge Society. It must be borne in mind that the Knowledge Society collects a large amount of

\footnotetext{
${ }^{*}$ Researcher, University of Pisa, Italy.
} 
evidence, projective materials, concerns, doubts, ambitions and even poorly hidden intentions of dominion by the most advanced nations. Issues of power cannot be neglected insofar as they guide and strongly influence the processes under way: a very strong implication in the route towards the Knowledge Society that should be considered with particular attention concerns precisely the overall democratisation of processes, which in turn it cannot be only political but generally social and economic. The need to reflect on the content of knowledge as such is thus recalled: it is certainly a value which, although put forward as pre-eminent, does not guarantee security and stability - and we should speak of prosperity - in the contexts in which it is applied. Based on these considerations and far from being restrictive, in this work we will propose an analysis of the progress of the Italian route towards a democratic and inclusive Knowledge Society.

In the first part of the article we will present a reconstruction of the theoretical framework and a definition of the historical and cultural contexts in which the idea of the Knowledge Society was born and developed. In a second phase, in order to offer a critical analysis trend in these directions, we will examine the main European documents as part of an overall reconstruction of the political project and operational guidelines for the realization of a European Knowledge Society. We will then move on to an examination of the Italian case, and we will question the effective institutional will to support the process towards the Knowledge Society. In this sense, we will ask ourselves: what are the choices in the direction of concrete support to the sectors considered strategic? Which processes of transformation are under way and with what results? In an effort to come up with answers, albeit partial, to these questions, we will consider the data made available by the most accredited national and international research institutions, with a focus on public dynamics in education, training and research. Finally, after careful analysis of the controversial aspects of the Italian route towards the Knowledge Society, we will consider the possible ways out and strategies for going beyond the paradoxes of the Knowledge Society.

\section{The Knowledge Society: Concept and Theoretical Framework}

The expression Knowledge Society is now part of the common language and circulates swiftly between politicians, intellectuals and scholars from various disciplines who are attentive to trends in the development of contemporary societies. The current historical phase is characterised by the problematic advance of the processes of globalisation. Some of the significant drivers of change that clearly demonstrate the high degree of complexity in today's social systems include financialization of the economy, opening up international markets, new/net/knowledge economies, transformation of the workplace, intensification of information flows, multiplication of forms of communication and the consequent redefinition of individual-society relations (Bauman 1998, Giddens 1990, Martell 2010). In this context, the concept of the 
Knowledge Society seems to be primarily configured as an attempt to provide an analytical summary of the transformations taking place, to then return to an operational vision of the future on which to normatively base political actions aimed at the definition of a new model of society. People speak about a Knowledge Society and, in doing so, set forth a need and identify a way ahead that will not be subject to deviations, whatever the current social changes may be. Regarding the idea and the need for a Knowledge Society, many scholars have put forth their theories and differing perspectives have emerged out of this international debate (Cerroni 2006, Gallino 2007, Pastore 2009, 2013, Stehr 1994).

Peter Drucker was one of the first scholars to use the expression

"Knowledge Society" in his studies about the transformations of capitalism and production systems (Drucker 1969:19). The revolution he announced is the revolution of knowledge management, which would replace the worker management of the Taylorist and Fordist era. He refers specifically to changing employment structures and to the growing importance of human capital in new forms of work organisation (Drucker 1993).

Knowledge is identified as the strategic resource whose management is deemed crucial for the success and competitiveness of individual businesses, as well as entire social and economic systems.

This position is not entirely new, if we consider that classical economics has always recognised the important role played by knowledge in the production of wealth. In the Principles of Economics (1890) by Alfred Marshall we read that "Capital consists in a great part of knowledge and organization [...] Knowledge is our most powerful engine of production [...] Organization aids knowledge" (Marshall 1890:IV.I.2.). Austrian economists Friedrich von Hayek and Joseph Schumpeter considered taking the knowledge factor into account fundamental for economic activities. While Hayek (1945) highlights the importance of tacit, specific knowledge of contest and of spatiotemporal circumstances, Schumpeter (1951) stresses the importance of continuous recombination of explicit knowledge.

In any case, an economy of knowledge should propose significant investments in Research and Development (R\&D) and in marketing activities, thereby assigning decreasing percentages of production expenses (substantially related to raw materials, production techniques and workforce) in relation to the final costs. In similar contexts, competitiveness is characterised by specific factors, representing systemic prerequisites for the full realisation of economies founded upon information and knowledge: 1) the presence of big industrial corporations, competitive on a global scale, with ample investment capacity for Research and Development; 2) the availability of plentiful public funds for universities and for financing basic and applied research; 3) the high creation rate of innovative start-ups in boundary pushing technological fields, arising as spin-offs from big corporations, universities and public research institutes; 4) the capability to finance innovative, high-risk businesses with venture capital societies supporting the creation and development of new enterprises (Rullani 2004) 
Between the end of the 1960s and the beginning of the 1970s, the sociological debate about the new model of society started to become more and more heated (Kumar 1995). Many scholars assigned a relevant role to the development and diffusion of new information and communication technologies, in the context of the more general process of the transformation of contemporary societies (Bell 1973, 1987, Castells 1996). In this way, expressions like information society and knowledge society became increasingly used to denote the magnitude of the ongoing transformations. These are not interchangeable or overlapping labels, but rather intertwined and mutually complementary processes (Webster 2006).

According to Daniel Bell, "the post-industrial society is an information society, as the industrial society is a goods-producing society" (Bell 1973: 467).

As a matter of fact, the Harvard sociologist would soon start to replace the expression "post-industrial society" with "information society" in his writings. Splitting society in three realms - Techno-economic structure, Polity, and Culture - Bell seems to assign the lead role to the techno-economic structure, considering it as the favoured relation through which social change is built. Bell's post-industrial society is a theoretical model (an ideal type, as Weber would have said) developed on the basis of some structural tendencies observed in the U.S.A.: 1) the shift of the main economical component (transition from a manufacturing economy to a service economy); 2) the imbalance in favour of the tertiary sector (pre-eminence of professional, technical and white-collar class); 3) the new centrality acquired by theoretical knowledge as a source of innovation and of public policy creation; 4) the need to foresee and anticipate the future; 5) the establishment of a new "intellectual technology" aimed at a decisional logic (Mattelart 2002:69-75).

Overall, he presents the transition from material to immaterial, from hardware to software, from realisation to design, from markets to networks. As previously stated, these steps are connected to the spreading and progressive development of Information and Communication Technologies (ICTs).

At this stage, it can be useful to focus on the major theoretical contribution offered in this direction by another contemporary scholar, the Spanish sociologist Manuel Castells. His reflection is centred on the concept of informationalism, and according to him "the term informational indicates the attribute of a specific form of social organization in which information generation, processing, and transmission become the fundamental sources of productivity and power because of new technological conditions emerging in this historical period" (Castells 1996: 20). In this way, a new technological paradigm is presented, the characteristic elements of which may be summarised as follows:

"The first characteristic of the new paradigm is that information is its raw material: these are technologies to act on information, not just information to act on technology, as was the case in previous technological revolutions. 
The second feature refers to the pervasiveness of effects of new technologies. Because information is an integral part of all human activity, all processes of our individual and collective existence are directly shaped (although certainly not determined) by the new technological medium.

The third characteristic refers to the networking logic of any system or set of relationships using these new information technologies. The morphology of the network seems to be well adapted to increasing complexity of interaction and to unpredictable patterns of development arising from the creative power of such interaction [...].

Then, a fifth characteristic of this technological revolution is the growing convergence of specific technologies into a highly integrated system, within which old, separate technological trajectories become literally indistinguishable. Thus, micro-electronics, telecommunications, opto-electronics, and computers are all now integrated into information systems" (Castells 1996: 71-72).

The new paradigm and the Network Society theorised by Castells do not qualify as an overcoming of capitalism, rather they favour its expansion and pervasiveness from a global perspective:

"Capital accumulation proceeds and its value-making is generated, increasingly, in the global financial markets enacted by information networks in the timeless space of financial flows. From these networks, capital is invested, globally, in all sectors of activity: information industries, media business, advanced services, agricultural production, health, education, technology, old and new manufacturing, transportation, trade, tourism, culture, environmental management, real estate, warmaking and peace-selling, religion, entertainment, and sports" (Castells 1996:503).

What appears to be particularly remarkable about Castell's reflection is the idea of the open system, where the structural dimension increasingly intersects with the valorisation of so-called immaterial resources:

"the information technology paradigm does not evolve toward its closure as a system, but toward its openness as a multi-edged network. It is powerful and imposing in its materiality, but adaptive and open-ended in its historical development" (Castells 1996:75-76).

It is essential to highlight that the social dimension within which Castells positions the historical development of the Network is an example of what he defines as milieux of innovation. The reference here is clearly to the entrepreneurial culture spread in the multiform structures that have appeared in Silicon Valley since 1970, where, favouring innovative and anti-bureaucratic tendencies, creating a space for experimenting with the results obtained through free and cooperative programming. This has taken the form of a kind of revolution of information technology, contributing to the formation of these 
innovative contexts, where discoveries and applications are able to interact and be tested:

" in a recurrent process of trial and error, of learning by doing; these milieux required (and still do in the early twenty-first century, in spite of on-line networking) the spatial concentration of research centers, highereducation institutions, advanced-technology companies, a network of ancillary suppliers of goods and services, and business networks of venture capital to finance start-ups. Secondly, once a milieu is consolidated, [...] it tends to generate its own dynamics, and to attract knowledge, investment, and talent from around the world" (Castells 1996:65).

This led to the spreading of the idea of learning organisation, i.e. an actual cognitive system that restores the image of dematerialised organisations and businesses, the distinctive features of which should be determined by the cognitive nature of the environment, the pervasiveness of knowledge and skills and also the relationship networks developed within and outside workplaces.

Japanese scholars Nonaka and Takeuchi (1997) described this situation using the model of the "Knowledge Spiral". They envisage a cycle structured into four phases that begins with an exchange of tacit knowledge (socialisation), and then continues with a process of knowledge externalisation that makes this knowledge explicit. The combination of tacit and explicit knowledge results in a new level of tacit knowledge being generated, and this new tacit knowledge is absorbed from the organisation (internalisation). As such, the cycle starts again, and the process goes on.

Considered in a similar manner, learning is essentially the result of the dissemination of knowledge accumulated over time and the production of new knowledge. It follows that the level and quality of processes and training (whether formal or informal), as well as operational and relational experiences, become absolutely crucial. As such, as learning is found to be primarily linked to the commitment and determination of the subject in question, it undergoes a further strengthening in contexts whereby the cognitive stimuli are varied and ongoing. In this sense, knowledge is also a relational experience. Therefore, investing in knowledge is fundamental not only for its positive impact on growth, but it could (and should!) have a profound effect in raising the public spirit (Visco 2014). This is a potentially important contribution to the social cohesion and well-being of the citizens. The problem that remains to be solved is how these aims can be pursued effectively and under what political strategy.

\section{The European Political Strategy for a Knowledge Society}

From the concept of permanent education launched by UNESCO in the 1970s to the most recent European Commission documents, an idea of progress based on knowledge has been spread and become established. Knowledge is considered to be the right tool for guaranteeing widespread prosperity, by 
ensuring the development of the individual, society and the economy (Delors 1996).

The plan, from the content of the European Community Commission reports, seems to be clear. Having singled out unemployment as the single most important problem facing European countries, it is crucial to find suitable solutions. It is no longer enough to increase Gross Domestic Product in order to raise employment levels. Economic growth requires so-called 'active work policies' in parallel to it.

The immediate objectives of this European strategy are training and instruction, both of which are capable of helping to prepare workers and school-leavers professionally in order to face the changeable requirements of the work market. According to the Delors Report (Commission of the European Communities, 1993), the basic principle at the root of each training scheme should be the valorisation of human resources throughout their active lives. The objective of this is to "learn how to learn throughout life". In order to facilitate the passage of school-leavers onto the job-market, broader forms of internships and apprenticeships within companies will be made available, coupled with short, very practical professional training courses due to be organised in specialised centres.

The White Paper of November 1995, Teaching and Learning towards the Learning society (Commission of the European Communities 1995), reiterates the same issues and states that in order to build a Knowledge Society it is necessary to: encourage the acquisition of new knowledge; bring schools and enterprises closer together; combat exclusion; develop proficiency in three European languages and treat capital investment and investment in training on an equal basis.

The same philosophy inspired the strategic goal of the European Council of Lisbon in 2000: "becoming the most competitive and dynamic knowledgebased economy in the world, capable of sustainable economic growth with more and better jobs and greater social cohesion".

Almost in parallel to the affirmation of the Lisbon Strategy, there has been a substantial change in the way higher education systems and generic education institutions work. These reforms were legitimised with the Sorbonne Declaration in 1998 and with the subsequent Bologna Process in 1999 for the establishment of a "European Space of Higher Education".

Overall, the documents taken into account outline a path that, starting from the identification of a material problem, such as unemployment, seems to lead to the elaboration of a wide and progressive strategy. From the Delors White Paper to the Lisbon objectives, we can observe the expansion of the perspective leading to the individuation of a goal to be shared and proposed as valid for the whole European Community. Formulations in this direction are accelerating and rapidly escalating, with obvious associations to more general dimensions of culture.

Probably for the first time, the vision of a common European destiny, beyond the economic, financial and regulatory processes, has started to appear with the Bologna Process. It should be noted, however, that, beyond a 
terminology that converges towards the same idea of a knowledge society, a serious assessment of the progress made on this path must refer to different conceptions of the role and functions of education and training, and requires a serious reflection on the effectiveness of the actions taken by educational and training institutions (Pastore 2015).

The ongoing monitoring of the Lisbon Strategy progress has highlighted how, despite successes in some important sectors, there are still evident growth, employment and innovation difficulties, especially in the largest Eurozone economies, and the ongoing economic-financial crisis has further aggravated the overall situation (Crescenzi 2011). Hence the relaunching of the "Europe 2020" Strategy, as a way out of the crisis, in line with the Lisbon proposals, confirms that the path towards the knowledge society is unavoidable.

\section{The Italian Route towards the Knowledge Society}

This part of the work considers the progress of the Italian route towards the knowledge society. How Italy is positioned within this political project? What are the concrete choices that support the sectors considered to be strategic? Which processes of transformation are under way and with what results?

With regard to the Italian situation, the statistical data released by the most accredited national and international research institutes indicate delays in almost all the areas considered strategic for the construction of the Knowledge Society. In fact, the public investments in education, training and research are among the lowest in the European countries.

In order to evaluate the policies produced concerning the areas of growth and human capital, spending on education and training, as measured in relation to Gross Domestic Product (GDP), is emerging as a key indicator that makes it possible to quantify, at a national and international level, how much countries are investing to improve facilities and encourage teachers and students to take an active part in the educational process. In Italy, the percentage of GDP devoted to education and training has been in decline since 2009, falling from $4.8 \%$ in 2009 to $4.1 \%$ in 2013 (ISTAT 2016). The European Countries (EU-28) spend about $5 \%$ of their total GDP on education, ranging from more than $6 \%$ spent by Iceland (7.7\%), Denmark (7.2\%), Finland (6.4 \% of GDP) and Belgium (6.3\% of GDP), to the $4.5 \%$ or less spent by Greece $(4.4 \%)$, Italy and Spain (4.1\%) (EUROSTAT 2016).

Generally, countries should invest in education and training to help foster economic growth, enhance productivity, contribute to personal and social development, and reduce social inequality, among other reasons. This is not always possible; during economic downturns, even core sectors like education and training can be subject to budget cuts. However, with reference to the Italian case, the financial and economic crisis shows all the weaknesses of the public system. 
The data reported, while taking the form of minimum indications, mark the absence of a strategic vision, or rather the obvious contradiction between the propagandistic celebration of the importance bestowed on education and training, and the vicious spiral of reduced public investment in these directions.

Another testing ground for "Italy as a Knowledge Society" is research. Without research, the very idea of the knowledge society is nullified, and it becomes a mere demagogic exercise in discussing development and innovation. Indeed, one of the targets set in the framework of the "Europe 2020" strategy deems it essential to achieve an appropriate balance between spending on research and development (R\&D) and GDP, in order to boost levels of productivity, employment and social welfare. Unfortunately, satisfactory results have not been recorded in these contexts either. In particular, public-private partnerships have stayed at very low levels. Over the last 10 years, the intensity of expenditure on $R \& D$ in Italy grew by only 0.24 percentage points, insufficient progress to close the gap with other European countries. Spending on R\&D as a percentage of GDP is still below the EU average (equal to $2.03 \%$ ), and far from the national objective for $2020(1.53 \%)$ and even further from the European target of 3\% (EUROSTAT 2016).

Even in this case, the absence of a strategic vision is evident and is the major problem. In addition, it is appropriate to question deficiencies in the Italian productive apparatus, which proves to be altogether too archaic, from both the production process and managerial-programmatic points of view. Several scholars, in fact, invite us to focus on the backwardness of Italian capitalism, on the weaknesses of the entrepreneurial class and on a series of bad habits that have been consolidated over time (Gallino 2003, 2005, Maddaloni 2016, Toscano 2011, Vasapollo 2007). The route towards the Knowledge Society (to highlight a crucial issue) is definitely slowed down by the poor constructive and synergistic relationship between training and production processes. The much-celebrated lifelong learning is only at the beginning of its possible trajectory; initiatives are still too modest for considering them a scaling event, nor for that matter can they take on the burden of deficiencies found elsewhere (secondary school and university). According to the documentary evidence, the communicative inability among the various levels of education once again produces distortions, overlapping and disorders for which it is difficult to imagine solutions in today's situation. The Italian national economic system - but in particular the members of that system - certainly pays the price, forced to "difficult" recoveries and mediations which necessarily reduce the rate of citizenship of everyone.

These unflattering results do not at all favour the necessary renewal of the economic fabric, especially that arising from the rapid growth of innovative enterprises and employment in highly knowledge intensive sectors. In fact, the apparent disinvestment in knowledge has adverse effects on the overall functioning of the school and university system. The skills of students, and also those of adults, are in decline. This in turn results in a decrease in the motivation of Italians to pursue university courses and higher education (De 
Mauro 2010, Solimene 2014). The real paradox seems to be the mistaken belief that studying is not very cost effective, which is recently spreading.

This false belief that studying is useless (certainly also fuelled by a bad press and bad politics) is undoubtedly due to the labour crisis and the growth of inequality. In times of crisis, in fact, social inequalities have increased and, as often happens, it is the weakest sector of society and the younger generations that pay the highest price. For them, studying risks becoming an unaffordable luxury; they are forced to give priority to work and, without qualifications, are often condemned to precarious and poorly paid work. In this scenario, the school dropout rate continues to be above the EU average. Furthermore, the percentage of young people between 15 and 24 who are neither working nor in education or training (NEET) has increased, rising from $16.2 \%$ in 2007 to $22.2 \%$ in 2013 (32.9\% in the $25-29$ age group) and is now the highest in the EU (European Commission 2015).

Yet the data show that study and higher education are still the best way to tackle the financial and economic crisis and find a stable job.

A careful reading ISTAT's findings regarding labour forces survey shows that, over time, having a degree still offers better employment conditions on average, and a distinct advantage in terms of income, at least for employees. In addition, the data reveals how the recent crisis in all the European countries, but especially in Italy, has caused a worsening of employment that is more intense for school leavers than university graduates, both for the labour force as a whole and for young people in particular (ANVUR 2014, AlmaLaurea 2015). Of course, the actual difficulties experienced by Italian graduates in finding adequate professional positions should not be overshadowed, as they are significantly higher than the average found in other European countries.

However, these difficulties should not detract from the value of study and the importance of training. A similar epilogue would encourage large slices of the population to slip dangerously downward and favour the emergence of new inequalities.

\section{Paradoxes and Possible Ways Out}

The analysis conducted thus far has highlighted some of the significant contradictions inherent in the Italian routes towards the knowledge society. There are various paradoxical elements at play: limited resources, low skills, narrowing of the cultural base, the absence of an overview of the system. Moreover, Italy remains a fragmented country, with large differences between the northern and southern regions (Gallino 2006, Maddaloni 2012). This problem is present in other European countries, but not to the same extent as in Italy. The fact that there is still a Southern Question (over 150 years after the Unification of Italy), which is often forgotten or dismissed as a criminal question, is indicative of both a historical failure of public policies, and the major structural difficulties in the processes of cultural transformation (Cassano 2009, Toscano 2011). This is a malaise that speaks of a clear 
separation between the State (formal legality) and civil society (de facto reality), as suggested by Gramsci's still relevant notes (Gramsci 1975: 2057).

What Gramsci noted in reference to the history of Italy is the missed encounter between nation and people; just remember that, in the writings of this author, the notion of people presents an internal dialectic "connected with its unfolding in a network of relationships, up to the relationship, even if problematic, with the social totality. It is evident that "people", associated with the "nation" does not refer to a part of a separate society, bearer of a need for political and cultural autonomy, of "spirit of division"; but rather to a part for which the relationship (positive or negative, organic or dismembered: here lies the question) with social-national totality is at stake" (Baratta 2003: 47). The aspects highlighted invite reflection on a poor national spirit, cause and consequence of that "petty and small" individualism against which Gramsci throws out sharp barbs on several occasions:

"Individualism is merely brutish apoliticism; sectarianism is apoliticism, and if one looks into it carefully is a form of personal following [clientela], lacking the party spirit which is the fundamental component of "State spirit". The demonstration that party spirit is the basic component of "State spirit" is one of the most critically important assertions to uphold. Individualism on the other hand is a brutish element, "admired by foreigners", like the behaviour of the inmates of a zoological garden" (Gramsci 1975: 1755).

The real paradox is that while we celebrate the knowledge society, Italy is actually always finding new forms of knowledge, with particularistic ties. Almost nothing in Italy seems to escape the logic of tainted proximity. "From the various forms of criminality to the various forms of policing, from the entrepreneurs to the unions, from the newspapers to the parliamentary factions, from universities to central and local authorities: no sphere can be said to be free from the assumption that only known people can be trusted" (Romitelli 2009:78).

Society appears to dissolve into a fine community dust, characterised by actions and, above all, by inaction.

Moving beyond the paradoxes of the knowledge society means, first of all, breaking down these borders, overcoming the fragmented culture and the logic of small gardens. To use another Gramscian expression, it means launching an "intellectual and moral reform" founded on a profound upheaval of human relationships of knowledge as an element of the construction of a political "hegemony" policy, understood as intellectual and moral direction (Gramsci 1975); this implies a total transformation of culture, of its production and its methods of dissemination (Frosini 2009). It means affirming the Society side in the expression Knowledge Society, to create new forms of solidarity and social ties. But it should be noted that "the economic reform programme is the concrete way to present every intellectual and moral reform" (Gramsci 1975: 1561). It has already been stated that the quantum of public resources made 
available to Italy for investment in strategic sectors (Education, Research, Innovation) ranks among the most modest of those recorded in developed countries. This deficiency greatly limits all aims for optimisation. But added to this, as this is happening, there is an inability to standardise a procedure that this prerogative would desperately need. Edgar Morin found the foundation of the inability to perceive and conceive fundamental and global problems to lie in the fragmentation and compartmentalisation of knowledge in noncommunicating disciplines.

"Hyperspecialisation shatters the complex fabric of reality; the primacy of the quantifiable obscures the emotional reality of human beings. Our parcelled form of knowledge produces global ignorance. Our mutilated way of thinking leads to mutilating actions. This is joined by the following limitations: 1) reductionism that reduces the knowledge of the complex units to those of the presumed simple elements that constitute it; 2) binarism, which decomposes into true/false that which is either is partially true or partially false or true and false at the same time; 3 ) linear causality, which ignores the retroactive ring; 4) Manichaeism, which sees only the opposition between good and evil" (Morin 2012:133).

This leads to the proposal of a necessary "reform of thought" that can restore the ability to grasp realities in their complexity and globality and:

- gather that knowledge of the parts depends on knowledge of the whole, and that knowledge of the whole depends on knowledge of the parts;

- recognise and treat multidimensional phenomena, instead of isolating each of them in their dimension in mutilating dimension;

- recognise and deal with realities that are both supportive and conflicting (like democracy itself, the system that feeds antagonisms while it regulates them);

- respect the different one while recognising the first one.

"A thought that isolates and separates should be replaced by a thought that distinguishes and unites. A disjunctive and reductive thought should be replaced by a complex thought in the original sense of the term complexus: that which is held together" (Morin 2000:91).

The way out, proposed by the French scholar, is that of a politics of civility, a new humanism capable of taking on the actual task of creating solidarity throughout the planet (Morin 2012). This is a paradigm shift that cannot only be limited to the logic of development, but should be extended to the values that society as a whole intends to pursue. However, it is important to be incisive to avoid reproducing further futuristic visions that are poorly equipped to make sense of the transformations taking place.

The idea of the state as in decline, being overtaken and weakening has been discussed multiple times with reference to the processes of globalisation. 
Many expressions can be used to designate the loss of state functions and lament the fact of its deterioration in the face of stronger institutions. Nevertheless, the state continues to be a leader, willing or not, in everyday life, in the organisation of assistance for its members and in the planning and training of their civil bases (Borghini 2009). Italy's problem is still that of not being able to find a convincing answer to the question: what citizenship for what citizen?

\section{Concluding Remarks}

The Italian path to the knowledge society continues to be completely abstract in its quantitative and qualitative disparities, and for this reason it is still inadequate. The lack of planning, because that is what it is, can be even theorised in the framework of a liberalism that leans, perhaps unwittingly, towards a de facto social Darwinism. Here is where the old arts and ancient vices are re-established, where new vocations and new virtues are required. In fact, it is not possible to think of a knowledge society without vocation and without virtue. The whole framework that supports it would collapse and the sources from which it takes inspiration would be undermined.

A knowledge society requires a policy for knowledge, and the state must recover its function as a guide through the delicate transition from theory to practice. This is a reversal of the trend that should be based on the revival of public policies supporting knowledge and culture, as sources of social welfare (Innerarity 2013, Stiglitz et al. 2013). In fact, development seems increasingly bound to the activation of a virtuous relationship between strengthening research, increasing education levels and training the population, repositioning the production systems in the direction of innovation, quality and sustainability. Thus, as mentioned, education, training and research take on a decisive role in a modern concept of citizenship and economic planning, and, in this perspective, cognitive work can regain sense, dignity and value.

To guide the reform of the systems of knowledge and make up for the delay Italy has accumulated in many areas, it is necessary once again to give meaning to constitutional values. It is necessary to reaffirm knowledge as a basic right for the exercising active citizenship. The public school should be the primary factor of inclusion and social mobility. Freedom of teaching and research should be established as essential principles. On this basis, an authentic re-publicisation of knowledge systems would allow the possibilities that reside in the idea of the open system to be fully carried out and to enhance their participatory effects. The recovery of the public meaning of the process should be interpreted and implemented as a collective re-appropriation of educational processes, like the new assumption of shared responsibility on the part of the entire community and all the individuals who go experience life at school, university and research institutions. The horizon of meaning can only be that of knowledge as a common good (Hess and Ostrom 2009), in order to renew democracy and public ethics. In the absence of such guidance, the whole 
Knowledge Society process would see the dominance of market logic and power that would further increase the gap in inequalities.

\section{References}

ANVUR 2014. Rapporto sullo stato del sistema universitario e della ricerca 2013. 1. Studenti e laureati [Report on the state of higher education and research 1. 2013. Students and graduate]. Roma.

AlmaLaurea (2015) Condizione occupazionale dei Laureati. XVII Indagine 2014 [Employment of Graduates. XVII Survey 2014]. Bologna.

Baratta G (2003) Le rose e i quaderni. Il pensiero dialogico di Antonio Gramsci [The roses and the notebooks: Antonio Gramsci's dialogical thought]. Roma: Carocci.

Bauman Z (1998) Globalization: The Human Consequences. Cambridge: Polity Press.

Bell D (1973) The coming of post-industrial society. A Venture of social forecasting. New York: Basic Books.

Bell D (1987) "The post-industrial society: a conceptual schema." In AE Cawkell (Ed) Evolution of an Information Society. London: Aslib.

Borghini A (2009) Potere simbolico e immaginario sociale. Lo Stato nella vita quotidiana [Symbolic and social imaginary power. The State in everyday life]. Trieste: Asterios.

Cassano F (2009) Tre modi di vedere il sud [Three ways to see the South]. Bologna: il Mulino.

Castells M (1996) The rise of the network society. Oxford: Blackwell Publishing.

Cerroni A (2006) Scienza e società della conoscenza [Science and Knowledge society]. Torino: UTET.

Commission of the European Communities (1993) Growth, competitiveness, employment. The challenges and ways forward into the 2lst Century. White Paper. COM(93) 700. Luxembourg: Office for Official Publications of the European Communities.

Commission of The European Communities (1995) Teaching and Learning towards the Learning society. White paper on education and training. COM (95) 590. Luxembourg: Office for Official Publications of the European Communities.

Crescenzi A (2011) "La Strategia 2020 e la nuova governance europea" ["The 2020 strategy and the new European governance"]. In M Decaro (Ed) Dalla strategia di Lisbona a Europa 2020. Roma: Fondazione Adriano Olivetti.

Delors J (1996) Learning: the treasure within. Report to UNESCO of the International Commission. Paris: Unesco Publishing.

De Mauro T (2010) La cultura degli italiani [Of the Italian culture]. F Erbani (Ed). Roma-Bari: Laterza.

Drucker, Peter. 1969. The Age of Discontinuity. Guidelines to Our Changing Society. London: Butterworth-Heinemann Ltd.

Drucker P (1993) Post-capitalist Society. New York: HarperBusiness.

EUROSTAT (2015) Statistics on young people neither in employment nor in education or training. http://bit.ly/2a15c3S. [Accessed 10 June 2016].

EUROSTAT (2016) Government expenditure by function for European Union (28 countries). Retrieved from http://bit.ly/2cxwA9g. [Accessed 27September 2016].

Frosini F (2009) "Riforma intellettuale e morale" [Moral and intellectual reform]. In G Liguori, P Voza (Ed) Dizionario gramsciano 1926-1937. Roma: Carocci. 
Gallino L (2003) La scomparsa dell'Italia industriale [The disappearance of industrial Italy]. Torino: Einaudi.

Gallino L (2005) L'impresa irresponsabile [The irresponsible company]. Torino: Einaudi.

Gallino L (2006) Italia in frantumi [Italy shattered]. Roma-Bari: Laterza.

Gallino L (2007) Tecnologia e democrazia. Conoscenze tecniche e scientifiche come beni pubblici [Technology and democracy: Technical and scientific knowledge as public goods]. Torino: Einaudi.

Giddens A (1990) The Consequences of Modernity. Cambridge: Polity Press.

Gramsci A (1975) Quaderni del carcere [Prison notebooks]. V Gerratana (Ed). Torino: Einaudi.

Hayek F (1945) "The Use of Knowledge in Society." American Economic Review 35(4):519-530.

Hess C, Ostrom E (2009) La conoscenza come bene comune. Dalla teoria alla pratica [Knowledge as a common good. From theory to practice]. C Hess, E Ostrom (Eds). Milano: Bruno Mondadori.

ISTAT. 2016. Noi Italia. Cento statistiche per capire il paese in cui viviamo [We Italy. Percent statistics to understand the country we live in]. Retrieved from http://bit. ly/1kZfIVf. [Accessed 10 June, 2016].

Innerarity D (2013) The democracy of knowledge. New York, London: Blumsbury.

Kumar K (1995) From post-industrial to post-modern society: New theories of the contemporary world. Oxford: Blackwell Publishing.

Maddaloni D (2012) "Italia." In D Maddaloni (Ed) Il mondo contemporaneo. Un lessico sociologico, 95-106. S. Maria Capua Vetere- Caserta: Ipermedium.

Maddaloni D (2016) "Whatever happened to Italy? The Crisis of the Italian Pattern of Development in the Era of Globalization." Athens Journal of Social Sciences 3(4).

Marshall A (1890) Principles of economics. London: Macmillan and Co.

Martell L (2010) The sociology of globalization. Cambridge: Polity Press.

Mattelart A (2002) Storia della società dell'informazione [History of the information society]. Torino: Einaudi.

Morin E (2000) La testa ben fatta. Riforma dell'insegnamento e riforma del pensiero [The head well done. Education reform and reform of thought]. Milano: Raffaello Cortina.

Morin E (2012) La via. Per l'avvenire dell'umanità [The way: For the future of humanity]. Milano: Raffaello Cortina.

Nonaka I, Takeuchi H (1997) The knowledge creating company. Milano: Guerini.

Pastore G (2009) Verso la società della conoscenza. Analisi e critica del caso italiano [Towards a knowledge society: critical analysis of the Italian case]. Firenze: Le lettere.

Pastore G (2013) "Le società contemporanee come società dell'informazione e della conoscenza: possibili letture." In MA Toscano, A Cirillo (Eds) Sulla razionalità occidentale. Processi, Problemi, Dialettiche. Milano: FrancoAngeli.

Pastore G (2015) L'Italia della conoscenza. Ritardi, retoriche e opportunità [Italy of knowledge. Delays, rhetorics and opportunities]. Pisa: Pisa University Press.

Romitelli V (2009) Fuori dalla società della conoscenza. Ricerche di Etnografia del pensiero [Outside the knowledge society. Ethnographic research of thought]. Roma: Infinito edizioni.

Rullani E (2004) Economia della conoscenza. Creatività e valore nel capitalismo delle reti [Knowledge economy. Creativity and value in network capitalism]. Roma: Carocci. 
Schumpeter J (1951) The theory of economic development. Cambridge: Harvard University Press.

Solimene G (2014) Senza sapere. Il costo dell'ignoranza in Italia [Without knowing. The cost of ignorance in Italy]. Roma-Bari: Laterza.

Stehr N (1994) Knowledge societies. London: Sage.

Stiglitz JE, Sen AK, Fitoussi JP (2013) La misura sbagliata delle nostre vite. Perché il PIL non basta più per valutare benessere e progresso sociale [Mis-measuring our lives: why GDP doesn't add up]. Milano: Rizzoli Etas.

Toscano MA (2011) Prove di società [Tests of society]. Roma: Donzelli.

Vasapollo L (2007) Storia di un capitalismo piccolo piccolo [History of a small little capitalism]. Milano: Jaca Book.

Visco I (2014) Investire in conoscenza. Crescita economica e competenze per il XXI secolo [Investing in knowledge: Economic growth and skills for the XXI century]. Bologna: il Mulino.

Webster F (2006) Theories of the information society (3rd ed). London \& New York: Routledge. 